\title{
Hyperthermia in Clinical Oncology
}

\author{
H.S. Reinhold and J. Overgaard
}

THE CLINICAL application of hyperthermia has a strong biological rationale [1-3]. Experimental and clinical srudies indicate that tumour control rates can be significantly enhanced if, for example, radiation therapy is combined with hyperthermia $[4,5]$. If a tumour is heated one or more times to a temperature of $43^{\circ} \mathrm{C}$ or higher for an hour, the probability of response or permanent control increases substantially.

Nevertheless, some important problems remain. After about 15 years of experiments and technological developments in heat delivery and temperature measurement, it is clear that the application of a hyperthermic dose of sufficient intensity to a tumour is not simple. In the past the tumour temperature was measured with one thermocouple several times to give the "tumour temperature". Nowadays continuous multipoint thermometry is available, which indicates that it is not justified to speak about the tumour temperature but rather about a distribution of temperatures, which is heterogeneous not only in tumour space but also in treatment time. At the fifth European BSD-Users conference, in Noordwijk aan Zee and Rotterdam, The Netherlands (18-19 May 1990), which focused mainly on the clinical application of loco-regional hyperthermia as an adjuvant to radiotherapy or chemotherapy, T-90 (the temperature reached in time and space by $90 \%$ of the sampled points) emerged as one of the better indices of the efficiency of hyperthermia and therefore the therapeutic outcome $[6,7]$. The hyperthermic level achieved depends not only on the amount of energy deposited in the tumour tissue but also on the cooling effect of blood flow [8,9]. Many heating methods have been tried: electromagnetic devices (refs. 10-12 and L. Baert et al.), ultrasound [13], systems based on interstitial brachytherapy [14, 15] and perfusions with heated solutions [16, 17]. Important advances reported at the meeting included online evaluation of temperature distribution of modern hyperthermia equipment in conjunction with the development of mathematical models (refs. 18 and 19 and A.P.M. Zwamborn and P.M. van den Berg) to optimize heat application during treatment $[20,21]$. For the immediate future it seems realistic to add non-invasive thermometry to the hyperthermia equipment as an important aid in localizing power distribution in the patient.

Apart from these technological developments, a serious concern was whether currently used experimental tumour systems are of any value for clinical research in hyperthermia (ret. 8 and S.B. Field et al.). This is a key issue because progress in clinical hyperthermia, with its strong dependence on factors such as sequence and interval with radiation [2] and chemotherapy [22], is derived from animal models [2]. Thus the question of the number of hyperthermia treatments required for optimum

Correspondence to H.S. Reinhold, Dr Daniel den Hoed, Cancer Center, P.O. Box 5201, 3008 AE Rotterdam, The Netherlands.

H.S. Reinhold is at the Institute of Applied Radiology and Immunology (ITRI-TNO) Rijswijk, and at Erasmus University, Rotterdam; J. Overgaard is at the Institute of Cancer Research, Radiumstationen, Aarhus, Denmark. effect, as well as the sequence and interval between the modalities, is much discussed [23]. No consensus was reached at the meeting, other than that the treatment should be at a sufficiently high temperature (preferably $43^{\circ} \mathrm{C}$ ) and last for about an hour.

An encouraging observation is that all the retrospective analyses of superficial hyperthermia (e.g. carcinoma of the breast and recurrences of this tumour $[4,24]$ and head and neck nodes) indicate that with increasing hyperthermia treatment level, significantly higher response rates are obtained $[6,7,25]$. In addition, some prolonged complete responses in pelvic chondrosarcoma were reported by the paediatric oncology scrvicc in Paris. The current indications for successful adjuvant deep hyperthermia are found mainly in sarcomas [6, 24-26] and abdominal carcinomas, especially those of the cervix, colon and rectum [24]. There is also a need to improve the present results in bladder carcinoma [27]. In addition, an increasing number of encouraging results with thermochemotherapy, applied regionally or with perfusion, are being reported [17]. The meeting emphasized that hyperthermia is finding a definite place in the treatment of cancer.

As regards assessing the impact of hyperthermia on health care, a prospective cost-benefit analysis is being done by the Department of Economics at Erasmus University, Rotterdam, based on the results from the Rotterdam phase III trial on loco-regional hyperthermia plus radiotherapy. Such analysis is important: determining the value of a new, cost-increasing treatment modality [28]. Preliminary findings suggest that for pelvic tumours the costs may be moderate (about 1800 ECU per life year saved).

The meeting emphasized that deep heating for the treatment of pelvic malignancies has become feasible, and that the results are encouraging. The Rotterdam phase III trial with the BSD2000 machine has been started to identify whether addition of this treatment will be of real benefit.

1. Jung H, Dikomey E. Some basic effects in cellular thermobiology. Recent Results Cancer Res 1988, 107, 104-112.

2. Overgaard J. The current and potential role of hyperthermia in radiothcrapy. Int $\mathcal{f}$ Radiat Oncol Biol Phys 1989, 16, 535-549.

3. Los G, Sminia P, Haveman J, Wondergem J, González-González D, $\mathrm{McVie} \mathrm{JG}$. Enhancement of platinum concentrations in peritoneal tumours atter intraperitoneal cisplatin treatment combined with half body hyperthermia. Proc Am Assoc Cancer Res 1989, 30, 603.

4. van der Zee J. Low dose reirradiation in combination with hyperthermia: a palliative treatment for patients with breast cancer recurring in previously irradiated areas. Int $\mathcal{f}$ Radiat Oncol Biol Phys 1988, 15, 1407-1413.

5. Myerson RJ, Perez CA, Emami B, et al. Tumor control in long term survivors following superficial hyperthermia. Int 7 Radiat Oncol Biol Phys, 1990, 16, 1123-1129.

6. Oleson JR, Dewhirst MW, Harrelson JM, Leopold KA, Samulski TV, Tso CY. Tumor temperature distributions predict hyperthermia effect. Int $\mathcal{Y}$ Radiat Oncol Biol Phys 1990, 16, 559-570.

7. Leopold KKA, Dewhirst M, Samulski T, et al. Utility of a frequency distribution of temperature model for preoperative hyperthermia with radiation of soft tissue sarcomas. Int $\mathcal{F}$ Radiat Oncol Biol Phys (in press). 
8. Vaupel P, Kallinowski F, Okunieff $P$. Blood flow, oxygen and nutrient supply, and metabolic microenvironment of human tumors: A review. Cancer Res 1989, 49, 6449-6465.

9. Feldmann HJ, Molls M, Hoederath A, Stuschke M, Sack H. Thermoradiotherapy of deep seated tumours: Relationships between blood flow temperature inhomogeneity and tumour response (Ct 4). Radiation Research Society 1990. 38th annual Meeting of NAHG, New Orleans, USA, p. 92.

10. Petrovich Z, Langholz B, Gibbs FA, et al. Regional hyperthermia for advanced tumors: A clinical study of 353 patients. Int 7 Radiat Oncol Biol Phys 1989, 16, 601-607.

11. Molls M, Feldman HJ, Adler S, Sack H. Regional hyperthermia-a feasibility study. Strahlenther Onkologie, 1989, 165, 717-720.

12. van Rhoon GC, Sowinski MJ, van den Berg PM, Visser AG, Reinhold HS. A ring capacitor applicator in hyperthermia: energy distributions in a fat-muscle layered model for different ring electrode configurations. Int $\mathcal{F}$ Radiat Oncol Biol Phys 1990, 18, 77-85.

13. Hunt JW. Principles of ultrasound used for hyperthermia. In: Field $\mathrm{SB}, \mathrm{Hand} \mathrm{JW}$, eds. An Introduction to the Practical Aspects of Clinical Hyperthermia. London, Taylor and Francis 1990, 371-419.

14. Fabre JJ, Chivé $M$, et al. Microwave interstitial hyperthermia controlled by multifrequency microwave radiometry: phase I trials. Innov Techn Biol Med 1990, 11, 236-248.

15. Visser AG, Deurloo IKK, Levendag PC, Ruifrok ACC, Cornet B, $\mathrm{GC}$ van Rhoon. An interstitial hyperthermia system at $27 \mathrm{MHz}$. Int f Hypertherm 1989, 5, 265-276.

16. Gilly FN, Sayag AC, Carry PY, et al. Chimio-hyperthermie intrapéritonéale (CHIP) dans le traitement des carcinoses péritonéales d'origine digestive. Rapport d'une observation et données physiopathologiques. $\mathcal{f}$ Chir (Paris) 1990, 127, 95-98.

17. Carry PY, Perdrix JP, Sayag AC, Lepape A, Gilly FN, Banssillon $V$. Relationship between continuous measured oxygen consumption (VO2) and body temperature (BT) during hyperthermia therapy. Intensive Care Med 1990, 16, S49.
18. de Leeuw AAC, Mooibroek J, Lagendijk JJW. Steering of SAR distributions in phantoms in the 'Coaxial TEM' regional hyperthermia system. Strahlenther Onkologie 1990, 166, 348.

19. Crezee J, Lagendijk JJW. Experimental verification of bioheat transfer theories: measurement of temperature profiles around large artificial vessels in perfused tissue. Phys Med Biol (in press).

20. Dijk JDP, González-González D, Blank LECM. In: Sugahara T, Saito M, eds. Hyperthermia Oncology 1988. Summary papers. London, Taylor and Francis, 1988, Vol, 1, 573-575.

21. Wust P, Nadobny J, Felix R, Deufhard P, Louis A, John W. Strategies for optimized application of annular-phased-array systems in clinical hyperthermia. Int $\mathcal{F}$ Hypertherm (in press).

22. Dahl $\mathrm{O}$, Mella $\mathrm{O}$. Timing and sequence of hyperthermia and drugs. In: Overgaard J, ed. Hyperthermic Oncology 1984. Summary papers. London, Taylor and Francis, 1984, Vol. 1, 425-428.

23. Kapp DS, Petersen JA, Cox RS, et al. Two or six hyperthermia treatments as an adjunct to radiation therapy yield similar tumor responses: results of a randomized trial. Int $\mathcal{f}$ Radiat Oncol Biol Phys (in press).

24. Kapp DS. Site and disease selection for hyperthermia clinical trials. Int F Hypertherm 1986, 2, 139-156.

25. Issels RD, Prenninger SW, Nagele A, et al. Ifosfamide plus etoposide combined with regional hyperthermia in patients with locally advanced sarcomas: A phase II study. $\mathcal{F}$ Clin Oncol (in press).

26. Schwegler N, Notter M. Hyperthermie-eine Zwischenbilanz, Schweiz W Schrift (in press)

27. Wijnmaalen AJ, Helle PA, Koper PCM, Seldenrath JJ, van der Werf-Messing BHP. Combined external beam and interstitial radiation for bladder cancer. In: Mould RF, ed. Brachytherapy 2, Proceedings of the 5th International Selectron Users Meeting, 1988, The Hague, The Netherlands. Leersum, Nucletron International B.V., 1989, 192-195.

28. de Charro FTh. The economics of technological change in health Biotherapy 1990, 2, 271-274.

\section{News}

\section{Tumour Response Monitoring}

A symposium on Tumour Response Monitoring and Treatment Planning will be held in Munich on 11-13 April 1991 to discuss recent advances and current developments in the field. The chairman of the symposium is Professor A. Breit and the meeting has been organised in close collaboration with the World Health Organization. Further information can be obtained from: ART 91 Scientific Secretariat, Institute für Radiologische Onkologie der TU, Ismaninger Strasse 15, D-8000 München 80, Federal Republic of Germany. Tel (49) 89414043 05, fax (49) 894140 4396.

\section{EORTC Addresses}

A reminder of the new EORTC addresses. The EORTC Executive Office is at 83 Avenue Mounier-Bte 10, B-1200 Brussels, Belgium-tel (32) 27741640 , fax (32) 27723675 . The EORTC Data Center is at 83 Avenue Mounier-Bte 11, B-1200 Brussels, Belgium-rel (32) 27741611 (randomisation only [32] 277416 16) fax (32) 27743545 .

\section{Société Français de Radiothérapie Oncologique}

The Société Français de Radiothérapie Oncologique will hold its first national congress in Paris on 22-23 November 1990. Further details can be obtained from the secretariat: SOCFI, 14 rue Mandar, 75002 Paris, France. Tel (33) 14233 89 94, fax (33) 140260444 .

\section{European Osteosarcoma Intergroup}

The 16th meeting of the European Osteosarcoma Intergroup was held on 17 April 1990 at the Netherlands Cancer Institute. Dr J. van der Eijken was announced as the new chairman of the group.

The Cambridge Data Centre reported on the progress of several protocols: 80861 has 239 patients with an average entry rate of 62 patients per year. So far 155 patients have stopped or completed therapy. A clear shift towards conservative surgery is indicated. 80862 has a total of 83 patients and further details 